Autonomy, Character, and Self-Understanding

\title{
Paul Katsafanas
}

Boston University

Autonomy, traditionally conceived, is the capacity to direct one's actions in light of self-given principles or values. Character, traditionally conceived, is the set of unchosen, relatively enduring traits and proclivities that influence, constrain, or determine one's actions. It's natural to think that autonomy and character will be in tension with one another, for two reasons. First, autonomy is defined in terms of self-chosen principles, character in terms of constraints on choice. Second, when we attribute an action to an agent's capacity for autonomy, we treat it as issuing from exercises of reflective, self-conscious choice; when we attribute it to the agent's character, we treat it as caused by potentially unreflective motives, emotions, and dispositions.

How deep does this tension run? Of course, the answer depends on which conception of autonomy and character we accept. For example, if we construe autonomy as authenticity — as acting in a way that's true to one's deep character- then there may be no tension whatsoever. ${ }^{1}$ On the other hand, if we conceive of autonomy as libertarian freedom - as the capacity to choose in a way that's wholly undetermined by factors external to the will- then there may indeed be a conflict. So, to answer our question, we need to render it more determinate. We need to fix a conception of autonomy and ask how character comports with it.

I want to work with the broadest possible account of autonomy. Thus, I'll begin, in Section One, by discussing core components that are shared by most accounts of autonomy. I suggest that autonomy requires the capacity to engage in causally efficacious, contentrestricted choices that are not determined by the motives upon which one is reflecting.

\footnotetext{
${ }^{1}$ Just so, if we interpret autonomy as orthonomy — as being appropriately responsive to the true and the good-then there's no obvious reason for thinking that character in general threatens autonomy. (Though, of course, certain types of character traits might undermine one's ability to be responsive to the true and the good.)
} 
Section Two briefly clarifies the notion of character. With this groundwork in place, Section Three considers the ways in which character can limit the scope of choice and influence the reasons upon which one acts. I argue that these limitations and influences present no problem for autonomy. However, Section Four articulates a different and more problematic way in which character affects choice. There, I argue that character can limit autonomy when it operates in a certain manner. As a first approximation, character limits autonomy when it influences the agent's choice in a way that, were she aware of it, (1) she would disavow the influence, and (2) the influence could no longer operate in the same way. Put a bit differently, I argue that character undermines autonomy when it generates reflectively unstable perceptions of warrant. Section Five considers some objections to this account. Section Six examines the way in which the effects of character are sometimes dissolved by self-understanding.

In short: I'll argue that the mere fact that character constrains and influences choice is unproblematic. What matters is a particular kind of surreptitious influence that character can generate.

\section{Analyzing autonomy}

Accounts of autonomy differ in their details, but tend to have a common core. Autonomy is typically treated as the ability to determine one's actions via episodes of selfconscious choice. Moreover, on many views there are restrictions on the possible contents of autonomous choices. I will explain these features in turn.

First, consider the ability to determine one's actions via episodes of self-conscious choice. This is a causal condition: one's actions must be suitably affected by one's choices. One's choice needn't be the only cause of one's action; but it does have to add something. To see why, consider the difference between deliberating about what to do and thinking about what someone else should do. Suppose I consider whether my neighbor should act on his desire for another serving of ice cream. In engaging in this kind of reflection, I do not take my thoughts to have any bearing on what the neighbor will actually do. But this is quite different from the ordinary case of first-person deliberation about action. When I deliberate about whether I should act on a desire for ice cream, I take my answer to settle the question of what I will do. I do not regard my reflection as a passive, theoretical inquiry that has no 
bearing on its subject matter; I do not regard myself as making predictions while waiting to see how things turn out. Rather, if I decide that I should act on some desire, I also take this to settle the question of whether I will.

This is why autonomy requires that the episode of choice must add something. Some philosophers say that choice must cause the action, but we can be more modest. Choice might cause action only in the way that the surfer riding a wave causes herself to move toward the shore: she modifies, but does not originate, a complex series of forces. In short, choice must enable one to redirect the vector of motives, so that one ends up performing different actions than one otherwise would have.

Many philosophers express this point by claiming that autonomous agents must be capable of choosing in a way that is not determined by the motives upon which they are reflecting. Leibniz famously claims that motives "incline without necessitating" (Fifth Letter to Samuel Clark, collected in Leibniz and Clark 2000, 37). Locke writes that the mind has "a power to suspend the execution and satisfaction of any of its desires." The mind can "consider the objects of [these desires]; examine them on all sides and weigh them with others. In this lies the liberty that man has" (Locke 1975, 263). And Kant agrees, writing that human choice "can indeed be affected but not determined by impulses... Freedom of choice is this independence from being determined by sensible impulses" (Metaphysics of Morals 6:213214). In short: these philosophers claim that the agent must have the ability to choose in a way that is not determined by the motives upon which she is reflecting. After all, selfconscious choice must be able to shift the vector of motives, and accordingly cannot be determined by it. ${ }^{2}$

I've also stipulated that these choices will be reflective or self-conscious. I don't want this requirement to be interpreted in an overly restrictive fashion; perhaps it's possible to act autonomously without engaging in explicit bouts of deliberation. Perhaps selfconsciousness engenders the capacity for autonomy but isn't required in each exercise of the capacity. I will remain neutral on these points, merely noting that most accounts of autonomy treat it as realized only in self-conscious agents.

\footnotetext{
2 I'm restricting the claim about causal determination — one's choice must be independent of the motives upon which one is reflecting, but not independent of all motives. Background motives may drive deliberation in unnoticed ways. I address this point in Katsafanas (2011).
} 
Let's move on to the second component. Many philosophers maintain that there are restrictions on the possible contents of autonomous choices. For example, Kant argues that only principles that are compatible with the categorical imperative can be autonomously willed; acting on any other principle will result it heteronomy. More modestly, we may want to rule out manipulated or ideologically driven choices. Or we might simply say that the agent must act for (what she takes to be) good reasons. These are what I will call content restrictions on autonomous choice. In this paper, I'm going to avoid taking any stand on particular content restrictions. I'll assume that there are some content restrictions, but I won't say anything determinate about what they are. This will allow the account to be more general.

\section{Character}

So we have an outline of what autonomy requires: the capacity to engage in causally efficacious content-restricted choices that are not determined by the motives upon which one is reflecting. What about character? Character is traditionally conceived as a set of relatively enduring traits or proclivities that influence, constrain, or determine choice. ${ }^{3}$ Consider some examples of character traits: boisterousness; sociality; introversion; love of children; penchant for adventure; impetuousness; cautiousness; resoluteness; insensitivity; competitiveness; deference; vanity; humility; compassion. These are relatively enduring in the sense that they tend to abide for long stretches of the person's life and are resistant to immediate change. I might be vain in childhood and humble as an adult; but it makes little sense to say that I'm a vain person on Tuesday and a humble one on Wednesday. Traits persist. And traits generate some resistance: I might just give up a desire or a passing fancy, but humility and vanity take sustained effort to change.

Further, traits seem to play an important role in constituting the person's identity. If you say, “Tell me about Alice_-what's she like?," one of the first and most informative things we will do is discuss some of her character traits. After all, we learn a great deal about a person by discerning her typical patterns of behavior. Moreover, one of the most

\footnotetext{
3 This view is widespread; for example, as I explain in the next section, although John Stuart Mill and Arthur Schopenhauer agree on little else, they both endorse this view of character. We can also find this view attributed to philosophers as early as Heraclitus (Fragment 119).
} 
important, most defining feature of a person is what he cares about, and character traits are, in part, specifications of the kinds of things that people care about, the kinds of things that strike them as most important.

I've said that character traits influence, constrain, or determine choice. It's easy to see how: they can operate by determining the goals that appeal to the person or by modifying the way in which the person pursues these goals. Part of the difference between the impetuous and the cautious person is that different possibilities occur to them, different options strike them as the thing to do, different things appear possible. The impetuous person will be more likely to take up mountain climbing than the cautious person; he'll be more likely to be attracted to it, to see it as alluring, to ignore the dangers and focus on the exhilaration. And, if the cautious and the impetuous person both decide to climb the mountain, they'll go about it in different ways.

So character traits can operate by affecting patterns of thought, making some options appear alluring and others aversive, influencing what we take seriously and what strikes us as not a live option, modifying the way in which we carry out our actions, and so on.

\section{A conflict between autonomy and character?}

Autonomy and character seem to threaten one another. After all, autonomy is defined in terms of the agent's ability to make choices that are not determined by the motives upon which he reflects, whereas character seems to operate both by generating motives powerful enough to constrain choice and otherwise affecting the outcome of the agent's choices. In short: autonomy seems to require unconstrained choice, whereas character operates precisely by constraining and influencing choice.

There are two traditional responses to this dilemma. First, we might argue for an attenuated conception of character, according to which character is in some way autonomously chosen. This is the route taken by some Kantians, who argue- to put it very roughly — that what look like character traits are actually self-imposed principles of choice: the brave and cowardly persons differ in the principles that they impose on themselves. The second option is to take the opposite tack, arguing for an attenuated conception of autonomy. On this view, choice may be entirely illusory, in the sense that each action is determined solely by the agent's character. Schopenhauer endorses that view, claiming that 
while various motives may play out in our conscious thought, we have a "fixed disposition and unalterable character" that determines the way in which we will act on these motives $(\mathrm{On}$ the Basis of Morality, 112). In other words, character and motives jointly determine action; self-conscious willing adds nothing. ${ }^{4}$ Or, if we adopt a more modest view, choice is at least severely limited by the agent's character. Consider in this respect Mill, who writes

given the motives which are present to an individual's mind, and given likewise the character and disposition of the individual, the manner in which he will act might be unerringly inferred...if we knew the person thoroughly, and knew all the inducements which are acting upon him, we could foretell his conduct with as much certainty as we can predict any physical event. (Mill 1988, 23)

These paths are familiar: either character is reduced to an act of choice or choice is collapsed into an emanation of character. One or the other is attenuated, and there seems to be no good way of reconciling the two.

I think these familiar paths simply lead us astray; if we look more closely at the way in which autonomy and character interact, we can see that both have a real role in the production of action, and neither threatens the other. Let me explain.

Autonomy, as analyzed above, requires that one have the capacity to make causally efficacious content-restricted reflective choices that are not determined by the motives upon which one is reflecting. So understood, autonomy does not require what we might term absolute freedom: having every conceivable action open to one and having no influences upon choice. It follows that although character traits constrain, influence, and perhaps determine choice, this alone provides us with no reason for thinking that they threaten autonomy.

To see this, notice that there are many features that constrain, influence, and determine choice but do not seem to threaten autonomy. Consider situational factors, such as the age in which I'm born, my nationality, my gender, and so on. The fact that I live in the twenty first century instead of the fifteenth generates a wide range of constraints on my choices: I'm not free to resist landed barons, to be a knight, to join a guild. In this sense,

4 This is complicated by Schopenhauer's distinction between empirical and intelligible character. Above, I'm focusing on empirical character. Schopenhauer has a notoriously obscure argument for the claim that while our empirical character is fixed, our intelligible character-our "will as the thing in itself" — is in fact chosen in an atemporal act of willing. 
there is an enormous range of constraints on my choices. But it would be very odd to think that this limits my autonomy. ${ }^{5}$

Moreover, many situational factors influence the difficulty of various choices without thereby impacting autonomy. Take two farmers, one in a barren rocky landscape and another in a fertile valley. The one will experience far more difficulty in farming than the other, but again it would be very odd to think that this renders the one less autonomous than the other. They face different choices and must surmount different obstacles, but for all that they may make these choices and pursue these actions autonomously. ${ }^{6}$

Character might operate in the same way: it might restrict the realm of reflective selfcontrol and change the available options without thereby limiting reflective self-control. Or it might render certain choices more difficult-it will be harder for the cautious person to climb the mountain - but again, this needn't threaten autonomy. After all, the agent's situation does the same: the untalented pianist is not less autonomous because he has to struggle to master the piano, and just so the tempestuous person is not less autonomous because he has to struggle to contain his anger. So we might think that character traits are just another aspect of our situation. The fact that one has a sullen rather than joyful character no more limits one's autonomy than the fact that one is born in the twentieth rather than fifteenth century.

Still, we might have qualms. I think most will agree that although one's situation can restrict the range of choices and affect the difficulty of choices, this does not undermine autonomy. However, many will claim that character is different; although it, too, operates by restricting choices and changing difficulties, it has a more direct bearing on autonomy. What is this difference? Perhaps the former factors constrain the range of choices open to me, but the latter do something deeper.

\footnotetext{
5 Of course, these aren't the only ways in which one's circumstances shape one's choices. Daniel Little discusses the idea that the historical period in which one lives can affect one's character so that, for example, those who lived through the Great Depression tended to have different character traits than those who did not. As he puts it, "differences in settings... lead to differences in psychology across cohorts" (Little, this volume, page ???).

${ }^{6}$ One might worry that some situational factors limit one's autonomy. For example, consider being born into slavery; doesn't that limit autonomy? It needn't. Here, I think we need to distinguish restrictions on freedom of action from restrictions on autonomy. Sartre famously claims that "the slave in chains is as free as his master" $(1993,703)$, and surely there's a sense in which this is correct: while the same actions and possibilities are not open to the slave and the master, they are both free to choose within the range of options that are present to them. (A guiding principle of my argument: not every problem with an agent has to be traced to a defect in autonomy. We can acknowledge that slavery is horrific without maintaining that slavery necessarily compromises autonomy.)
} 


\section{Two types of influence}

To explore this possibility, let's distinguish two ways in which character might influence choice. First, it might operate in the same way as situational factors, constraining the range of available options and rendering some options more difficult than others, but not impacting one's ability to select from among those options. That is, it might determine the realm of choice but not the outcome of choice. If the above analysis is correct, then this is inconsequential with regard to autonomy.

Second, character might operate within this restricted realm of options, influencing us to make one choice rather than another. Perhaps this is more important; perhaps this is where the threat lies. So let's look at this second kind of character influence.

To begin, consider a line from Nietzsche: "if one has character, one also has one's typical experience, which always recurs" (Beyond Good and Evil, Section 70). There's something to this. Character influences the way in which we interpret our situations. The irascible person sees annoyances and provocations everywhere. The covetous person sees another's success as a reason for jealousy and acquisitive desire. The adventurous person sees the steep mountain trail as affording opportunities for exhilaration, challenge, and delight; the cautious person sees it as a deathtrap.

Part of what happens in these cases is familiar from experiences of strong emotions. Consider an archetypal childhood scenario. I'm camping and someone has just finished telling a frightening story. In my fearful attitude, I see shadows as concealing dangers; I perceive the rustling in the bushes as threatening; an air of menace hangs over the world; I attend to each potential threat; and this heightened attentiveness to aspects of the world that I'd ordinarily overlook reinforce my initial fear. The emotion colors my perception of the world and finds itself confirmed by the very world that it has colored. Put differently, the emotion is self-reinforcing: my fearful attitude makes the world look worthy of fear, which perpetuates the fear.

I take it that this is familiar. And my point is that character traits can operate in the same way. Fear influences one's perception of a situation, modifying the perceptual saliences (I notice the rustling of leaves, whereas normally I wouldn't), leading me to interpret my surroundings in different terms (as fearful rather than comfortable, say), making 
different descriptions of the setting seem natural (as threatening and dangerous rather than enjoyable). ${ }^{7}$ Character traits do just the same. The irascible and sanguine persons both see the faces of the audience, but the former finds frowns and grimaces salient and interprets them as marks of hostility and disdain, whereas the latter finds nods and thoughtful expressions salient and interprets them as approval. And these appearances confirm the very traits that generate them, thereby reinforcing the traits. ${ }^{8}$

This is what Nietzsche means when he says that if one has one's character, one also has one's typical experience: character traits color and modify our experience. Now, some philosophers take the mere presence of these influences as potentially compromising autonomy. Hardened Kantians, for example, may want to claim that these sorts of effects have to be purged to make room for autonomous choice; we must "step back" from these influences and distortions and assess the situation in impartial terms. ${ }^{9}$ But nowadays I think few are tempted by that view. These influences are pervasive and inescapable. The irascible and sanguine persons will view the same situation differently; but it does not follow that there is some neutral, affect- and character-trait-free way of viewing the same situation.

Nonetheless, there is something interesting about these effects. They can be very difficult to detect, and for that reason nothing is more common than agents mistaking them for ineluctable elements of their situations. I just pointed out that these emotions and traits confirm themselves through the perspectives that they generate. Fear leads us to see the world as full of reasons for fear; irascibility leads us to see the situation as teeming with provocations and indignities. These appearances, which after all are generated in part by my own subjective states, seem to be objective elements of the situation. For, on the one hand, I may not even notice the subjective state (my own fear, my own irascibility) that generates these appearances. And, on the other hand, if I do notice the subjective state, it will seem to be warranted by the cast that the world has taken on (it's not that I'm fearful, but that the world is full of threats; it's not that I'm irascible, but that other agents are provoking me). In

\footnotetext{
7 See Neil Sinhababu's contribution to this volume for a related discussion of the way in which desire influences perceptual salience, the manner in which we act, and the vividness with which certain ideas strike us. ${ }^{8} \mathrm{I}$ address these points in more detail in Katsafanas (ms).

9 See, for example, Kant's claim that, "The Principle of apathy-namely that the wise man must never be in a state of affect, not even in that of compassion with the misfortune of his best friend, is an entirely correct and sublime moral principle of the Stoic school; for affect makes us (more or less) blind' (Anthropology \$75; second emphasis added).
} 
this way, my perspective on the world, though everywhere colored by my emotions and character traits, seems to contain not a trace of me.

However, we sometimes do notice, in moments of clarity, that our own emotions and character traits are altering our view of the situation. The irascible person might reflect on the fact that the sanguine person would not notice the frowns, or would take them as meaningless. He might see the contingency in his own view of the situation.

In its most overt and self-conscious form, the discovery of the contingency in our own perspectives is a hyper-reflective process. It requires seeing that one has a particular subjective state; noticing that this subjective state lends a certain aspect or cast to the world; and seeing that, were one to have another subjective state, the world would appear differently. In other words, it requires introspection, analysis, and the considering of a counterfactual. Hyper-reflective as it may be, though, it's clear that reflective individuals sometimes do engage in this process. For example, conversations about emotionally fraught situations often proceed in this way: I'm torn about my relationship with Jill, and Jim helps me to see how a different perspective on my troubles casts them in a new light. Literature also works in this way. Reading Othello, you see how someone consumed with jealousy views the world. You see how something as innocuous as a handkerchief can be fraught with significance for someone with the appropriate character traits or emotions.

How do these reflections on our perspectives relate to the potential tension between character and autonomy? First, notice that our attitudes upon discovering these kinds of influence on our perspectives are not uniform. Some effects on perspective are salutary. My love and affection color my perception of my child, but this is something I wholeheartedly embrace; I know that my perception is skewed, in the sense that another wouldn't view situations involving my child in quite the same way, but this hardly matters to me.

The perspective generated by this emotion certainly restricts and influences my choices. ${ }^{10}$ But it seems quite different from those influences to which I object. For example, suppose I regret my irascibility; I see how it influences my choice, I see myself becoming angry at details that I later regard as inconsequential. This limitation, which I deplore, seems to affect my capacity for reflective self-control in a different way. I think we are more inclined to see it as a real limitation on autonomy.

${ }^{10}$ For discussions of related matters, see for example Williams (1981, Chapter 10) and Cuypers (2001). 
Why, exactly? I lack the space to provide a full answer here. Instead, I'll simply point out that many of the character traits that constrain a person's choice are viewed by the person as constituents of her identity. Loving one's child or one's partner, being curious or adventurous, being impulsive or cautious, are the sorts of things that make a person who she is. And insofar as the person accepts these aspects of herself, they can be seen as selfimposed or at least self-affirmed constraints. The traits one rejects, however, seem different. They may be part of who one is, but they are not part of who one wants to be. And insofar as this is true, they cannot be viewed as aspects of ourselves that we do or would autonomously choose. Put simply: even if one of my character traits is ineluctable, the fact that I approve of it makes it deliberatively analogous to a trait that I have chosen, whereas the fact that I disapprove of it makes it function quite differently. (I discuss these matters in more detail in Katsafanas [2011]).

So there seems to be a difference between the influences we regard as salutary and those to which we object. And now let's consider something else. As I pointed out above, these influences are very difficult to detect; we're ignorant of many, perhaps most, of them. Among the influences of which we're ignorant, we'd reject some of them and accept others. Accordingly, we can ask what would happen were we to become aware of the way in which emotions and character traits influence our perspectives.

Go back to fear. I've heard the scary story, and I suddenly notice the leaves rustling around me. They're fearful, frightening, ominous - they suggest a presence in the woods, some obscure threat. But then I reflect: it's just the wind. My own fear is leading me to perceive a gentle breeze rustling the leaves as a source of dread. Upon recognizing this, my fear won't necessarily dissipate, and the leaves won't necessarily seem affectively neutral; it's likely that their rustling will still cause a bit of unease. But they won't exert their influence in quite the same way; something will have changed.

We can be more precise about what has changed by linking this to the content view. The content restriction says that acting autonomously requires acting on some restricted set of considerations (such as, for Kant, those that can be willed as universal laws). So suppose we consider a case of the following form: I take myself to be acting on a good reason, but my perception of the reason as good dissipates when I see how my character is influencing 
my perception of reasons. ${ }^{11}$ Amplify the rustling leaves case: I consider running to escape from the immanent danger, but see this as absurd once I recognize that my fear is leading me to interpret the effects of a gentle breeze as ominous.

I submit that it is influences of this kind-whether they are caused by character traits or attitudes_-that undermine autonomy. More precisely:

(Thesis) The agent A's, and takes her A-ing to be warranted by consideration(s) R. Consider the following counterfactual:

Suppose the agent had further knowledge of the particular ways in which her character traits and attitudes impact her perception of $\mathrm{R}$ as warranting $\mathrm{A}$-ing. If the agent would continue to take $\mathrm{R}$ as warranting $\mathrm{A}$-ing, then her character traits and attitudes do not compromise her autonomously A-ing. Otherwise, the agent's autonomy has been compromised by her character traits or attitudes.

In short: character can compromise autonomy by affecting the agent's perception of reasons in a way that, upon acquisition of self-understanding, the agent would disavow. ${ }^{12,13}$

I've given one illustration of this with the fear example, but let me provide another. Suppose that whenever I drive, I see the other drivers as irritating, provoking, and hostile. They always seem to cut in front of me, to drive dangerously, to block my progress, to slow down or speed up at just the wrong times. But then I reflect and notice that other drivers on

\footnotetext{
${ }^{11}$ Sometimes I see that my perception of the reason as good is due to my character (in the sense that if I had a different character I wouldn't see the reason as good), but I'm fine with this. For example: I see the steepness of the cliff as providing me with a good reason to climb it, and I see that this is due to my adventurousness, but my approval of this action doesn't dissipate.

12 Notice that the Thesis provides a necessary, not a sufficient, condition for autonomy. It asks whether the agent's character traits and attitudes undermine her claim to autonomously acting. However, even if the agent's character traits and attitudes don't undermine her autonomy, other factors might. For example, suppose the agent's perception of shoplifting as warranted by a need for cash is not undermined by the acquisition of further knowledge about her character traits. Nonetheless, this action might be heteronomous; Kantians, for example, could reach this conclusion by pointing to the fact that the maxim cannot be willed as a universal law. 13 This account bears some similarity to Harry Frankfurt's notion of wholeheartedness. To simplify a bit, Frankfurtian wholeheartedness obtains when the agent bears a higher-order attitude of acceptance or approval toward his lower-order desires (Frankfurt 2004). The Thesis differs in two ways. First, it focuses on one's perceptions of warrant rather than one's lower-order attitudes. Second, while the Thesis focuses on a kind of approval - in particular, an approval that consists in taking one's action to be warranted-it demands that this approval be stable in the face of further information about the action's etiology. I discuss a related point in Katsafanas (2011).
} 
the same streets seem not to be habitually angered by their driving. I begin to wonder whether my own irascibility is leading to a skewed vision of the other drivers. And, noticing my own irascibility, I come to disapprove of it. The next time a driver seems to cut in front of me, I initially see this as a slight, a provocation, and prepare to blast him with the horn; but then I realize that my own anger is leading to this view, and I no longer see this maneuver as a good reason for leaning on the horn. It is these kinds of influence that-so I suggest - compromise autonomy. Prior to this recognition, my autonomy had been compromised; with the recognition, it is not.

If this is correct, then autonomy requires neither an absence of influence nor an absence of constraint. Consider again the way in which my perspective on my child is skewed by my love and affection for her. These emotions operate in just the same way as irascibility. They lead me to see choices involving my daughter in a way that differs from the way that those without these traits would see them. But, were I aware of these influences, I would endorse them; I would continue acting in the same way. So here, although my choice is constrained and guided by my character traits and emotions, my autonomy seems not to be compromised. Constraint and influence is perfectly compatible with autonomy. It's the constraint and influence that depends for its efficacy on my own ignorance that is problematic.

\section{Objections}

According to the Thesis, a character trait is autonomy-undermining when it shapes my perceptions in ways that I would disavow if I were aware of them. But apparent counterexamples are likely to occur to some readers. These fall into two types: there are cases in which I should, but don't disavow influences; and there are cases in which I would, but shouldn't disavow influences. ${ }^{14}$

First, suppose a sadistic individual should, but doesn't, disavow the traits that lead him to enjoy inflicting suffering on others. We might take the fact that the individual has morally objectionable character traits to undermine his claim to autonomy. But wouldn't the Thesis label such an individual autonomous?

\footnotetext{
14 Many thanks to Julia Markovits for describing the potential counterexamples in this way, and for providing the second case.
} 
It needn't. Recall that the Thesis identifies a necessary, rather than a sufficient, condition for autonomy. The sadistic individual does fulfill the condition specified in the Thesis, so it won't be the mere fact that his character traits influence him that undermines his autonomy. Nonetheless, he might fail to fulfill other necessary conditions for manifesting autonomy.

Consider a second example, which has the opposite form: Huck Finn decides to protect his slave friend Jim, but takes this decision to be unwarranted; he sees it as motivated by his friendship, and he doesn't believe that friendship is a sufficient reason for flouting the laws and customs of his society. On my view, Huck is not acting autonomously, for, upon reflection, he does not regard his action as justified. We might think this is the wrong verdict; after all, Huck is doing the morally correct thing. In other words, we might think that agents can act autonomously even when they don't regard their actions as justified.

However, I think it is a mistake to classify an individual like Huck as autonomous. To be sure, this is a complex case: Huck is acting against pernicious, morally objectionable social norms, and for that reason he seems praiseworthy. However, he does view his action as unjustified. Consider how I first introduced the notion of autonomy. Searching for a neutral definition, I claimed that autonomy, traditionally conceived, is the capacity to direct one's actions in light of self-given principles or values. That's where the trouble with the above cases arises. Huck is acting in light of self-given principles or values, in one sense: he's rejecting the pernicious values of his society. But in another sense he isn't acting in light of self-given principles or values, for he doesn't yet regard resistance to slavery as justifiable. So Huck seems to me to represent an interesting middle ground. If his departures from the norms of his society become entrenched, such that he regards himself not as temporarily falling away from his view of the good, but as acting on the good, then he would be autonomous. As things stand, though, he is not autonomous.

More generally, then, I suggest that we distinguish the question whether the agent is autonomous from the question whether the agent is flourishing, acting in the morally correct way, acting rationally, and so forth. Not every defect in an agent has to be traced back to a defect in autonomy; just so, not every praiseworthy aspect of an agent has to be seen as a manifestation of autonomy.

\section{Self-understanding}


Suppose I'm right that character constrains freedom only when it fulfills the conditions set out in the Thesis. If so, the way in which one can alleviate these impacts and become increasingly autonomous is by discovering and working to correct them. There's no guarantee that I will be able to do so; some of these traits may be deeply ingrained, rooted in my habitual ways of responding to situations and socially reinforced. But the Thesis claims - to put it in a new way-that it is only my reflectively unstable perceptions of warrant that impact autonomy. The perceptions of warrant that dissipate upon further information about my own traits and emotions are the ones that compromise autonomy.

Notice that these influences are, in a sense, self-maintained. It is important to be clear here: I do not mean that these influences can be adopted and set aside at will. What I mean is that character traits of the problematic sort - the sort, that is, that the Thesis identifies-operate in a way that requires the agent to be ignorant of their influence. For once we identify the influence, it can no longer operate in exactly the same way. Suppose I recognize that I'm irascible, and I see that my irascibility leads me to perceive neutral situations as provoking-I may go on being angry, but I can't do this in quite the same way. I can no longer see myself as having good reason for blasting the horn, cutting off other drivers, and so on. I can do these things, to be sure, but I cannot do them in a non-akratic manner.

So the influences are self-maintained not in the sense that by noticing that I am irascible, I'll automatically cancel the trait's effect on my perception. Rather, character traits determine our perspectives; they determine the way in which we view the world. Some of these perspectives are optional or contingent; if we had different character traits, we'd see the world differently. To uncover the contingency of these perspectives, self-understanding is needed. And once that self-understanding is in place-once I see that my perception of A-ing as warranted is generated by an influence that I reject-I can no longer make my choices in quite the same way. ${ }^{15}$

\section{Conclusion}

\footnotetext{
15 If ignorance of one's character traits is potentially autonomy-undermining, might ignorance in general (including ignorance of straightforward factual matters) be autonomy-undermining? Although I cannot address this complex question here, I think such a view is tempting.
} 
I've argued that character in general does not limit autonomy, because it operates in the same way as situational constraints: it limits and changes the range of options, but does not determine which of these options the agent will select. However, I also argued that if character surreptitiously leads me to choose an option, and if upon reflection I'd disavow this surreptitious influence, then my character has limited my autonomy. So, for example, if I'm cowardly I have a different set of options open to me than does the courageous person, and moreover the set of options presents itself differently (different saliences, affects, and so on). This fact alone doesn't threaten freedom any more than the fact that a modern individual faces different options than a medieval individual. What does, however, threaten freedom is if the cowardice operates within this realm of choices such that, while it take myself to be choosing X because $\mathrm{Y}$ (e.g. to run because defeat is immanent), if I had deeper knowledge I'd see that it's more accurate to say that I'm choosing X because Z (to run because I'm needlessly fearful), and I'd disavow this. ${ }^{16}$

\section{References}

Cuypers, Stefaan E. (2001), Self-Identity and Personal Autonomy. Burlington, Vermont: Ashgate. Frankfurt, Harry, The Reasons of Love (Princeton, N.J.: Princeton University Press, 2004). Kant, Immanuel. (2006), Anthropology from a Pragmatic Point of View, Robert Louden (ed.), New York: Cambridge University Press.

Katsafanas, Paul (2011), “Activity and Passivity in Reflective Agency,” in Russ ShaferLandau (ed.), Oxford Studies in Metaethics 6: 219-254. --- (ms.), “The Moral Significance of Perceptual Experience.”

\footnotetext{
16 Thanks to the audience at the UNC Chapel Hill Workshop on Character for helpful comments and critiques. I am especially grateful to Julia Markovits and Iskra Fileva for challenging and insightful comments on the entire paper.
} 
Leibniz, G.W., and S. Clark. (2000), G.W. Leibniz and Samuel Clark: Correspondence, Roger Ariew (ed.), Indianapolis: Hackett Publishing.

Little, Daniel (2015???), “Character and History,” this volume, pages ???-???

Locke, John. (1975), An Essay Concerning Human Understanding. Oxford: Oxford University Press.

Mill, John Stuart (1988), The Logic of the Moral Sciences. Chicago: Open Court.

Nietzsche, Friedrich (1989), Beyond Good and Evil, translated by Walter Kaufmann. New York: Vintage.

Sartre, Jean Paul (1993), Being and Nothingness, trans. Hazel Barnes. New York: Washington Square Press.

Schopenhauer, Arthur (1998), On the Basis of Morality, translated by E.F.J Payne. Indianapolis: Hackett.

Sinhababu, Neil (2015???) Virtue and Desire, this volume, pages ???-???.

Williams, Bernard. (1981), Moral Luck. New York: Cambridge University Press. 